\title{
Epilepsy Clinic from General Hospital of Mexico
}

\author{
Ana L. Velasco* \\ Epilepsy Clinic and Unit of Functional Neurosurgery, Stereotaxic and Radiosurgery, General Hospital of Mexico, Mexico City, Mexico
}

The General Hospital of Mexico Epilepsy Clinic has been working since 1993 though it was legally constituted in 2006. The main goal is to provide the epileptic patient with high-quality medical and/or surgical treatment so that their quality of life improves significantly allowing their reincorporation to an independent, productive life. It is a multidisciplinary clinic that is formed by specialists in neurology, neurophysiology, neurosurgery, neuropsychology, radiology, and chemo-pharmaco-biology. It has three main pillars that are carefully intertwined: assisting patients, teaching, and research.

Assistance is the first pillar and a huge challenge. This is anticipated since epilepsy is one of the top three consultation issues in neurology and neurosurgery and due to the fact that the general hospital is a receptor institution for patients in the whole country. Patients with refractory seizures are the main concern since they are candidates for epilepsy surgery. The high costs or this type of surgery is not guaranteed in the general hospital, so this pillar is supported by the next two pillars: research and teaching.

Research is a fundamental pillar to improve patients' quality of life and improve medical and neurosurgical techniques. Our clinic is constituted by three National Research and Technology Council (CONACYT) researchers. This allows the production and implementation of research projects and, the most important, financial resources provided by the General Hospital Research Department and CONACYT. The resources obtained through research projects benefit directly our epilepsy patients. We have been able to obtain the state-of-the-art equipment and have been able to work with other national (National University of Mexico, Center for Research and Advanced Studies of Mexico) and international research centers such as University of California, Los Angeles, and Montreal Neurological Institute, joining knowledge and technology. The justification of all research programs lies on pillar one: assistance, the huge need in Mexican society, to treat efficiently and innovatively epileptic patients.

Teaching is the third pillar. Our mission in the epilepsy clinic is to form highly prepared experts in the medical and surgical treatments for epilepsy with an emphasis in the physiopathology and research. We have programs at several levels: for medicine and psychology undergraduate students, residents, and neurosurgeons from Mexico and Latin-American and MBs and PhDs in Medical and Biomedical Sciences. We firmly believe that the best researchers are formed in the early stages of their career. It is a way of living, a form of thinking, questioning dogmas, with an endless search for answers, instituted in ethical conduct, and with the goal of benefitting the epileptic patient. They are constantly tutored by a senior researcher, are included in consultations, surgeries, and academic sessions, and have their own research projects. In this special issue, some of them are included.

\section{Acknowledgments}

The author thanks the neuropsychology team for the support provided.

\section{Correspondence:}

Ana L. Velasco-Monroy

E-mail: analuisav@yahoo.com

DOI: 10.24875/HGMX.M19000005
General de Mexico. Published by

0185-1063/@ 2017 Sociedad Médica del Hospital General de Mexico. Published by under the CC BY-NC-ND license (http://creativecommons.org/licenses/by-nc-nd/4.0/).
Date of reception: 03-07-2017

Date of acceptance: 13-07-2017

Available online: 21-03-2019 Rev Med Hosp Gen Mex. 2019;82(1):3-3 www.hospitalgeneral.mx Permanyer México SA de CV. This is an open access article 